\title{
Vagal cholinergic control of gastric alkaline secretion in normal subjects and duodenal ulcer patients
}

\author{
S J KON 'UREK, NINA KWIECIEŃ, W OBTUŁOWICZ, P THOR, \\ J W KONTUREK, T POPIELA, AND J OLEKSY
}

From the Institute of Physiology Academy of Medicine, Kraków, Poland

SUMMARY Gastric alkaline secretion was determined in ranitidine treated healthy subjects and duodenal ulcer (DU) patients using gastric perfusion aspiration system and back titration of gastric perfusate to original $\mathrm{pH} 6 \cdot 0$. Basal alkaline secretion showed periodic fluctuations reaching peaks at phase III of the migrating motor complex (MMC) in the stomach. Mean basal alkaline secretion in healthy normals and DU patients averaged $1120 \pm 124$ and $880 \pm 72 \mu \mathrm{mol} / \mathrm{h}$, respectively and no correlation was found between basal and maximally stimulated gastric acid and alkaline secretion. Modified sham feeding in normal subjects and in DU patients increased this secretion to the peaks of about 28 and $36 \%$ of the maximal alkaline response to intragastric application of 16,16 dimethyl$\mathrm{PGE}_{2}$ in these subjects. Vagotomy did not affect significantly basal alkaline secretion but prevented the rise in alkaline secretion induced by modified sham feeding. Atropine $(5-20 \mu \mathrm{g} / \mathrm{kg})$ decreased dose dependently basal, and prevented the modified sham feeding induced alkaline secretion, while pirenzepine $(5-20 \mu \mathrm{g} / \mathrm{kg}$ ) had little influence on basal, and did not affect the modified sham feeding induced, alkaline secretion. This study shows that basal gastric alkaline secretion fluctuates in phase with gastric motor activity, and is similar in normal and DU patients. Vagal stimulation strongly increases alkaline secretion, the effect being abolished by vagotomy and atropine, but not by pirenzepine, suggesting the involvement of M2 rather than M1 subtypes of muscarinic receptors in this stimulation.

Alkaline secretion of the gastroduodenal mucosa has been shown in various species, including man, to be an active process contributing to the mucosal defence mechanisms, particularly against luminal acid. ${ }^{1-3}$

Recent studies in dogs revealed that alkaline secretion in fasted dogs fluctuates in phase with motor activity ${ }^{4}$ and increases after vagal stimulation. Studies in man confirmed similar increase in gastric alkaline secretion after sham feeding ${ }^{67}$ and its suppression after the administration of anticholinergics, suggesting that vagal cholinergic component plays an important role in the mechanism of this secretion.

This study was undertaken (1) to determine the magnitude and possible fluctuations of basal alkaline secretion with respect to gastric motor activity; (2) to compare the vagally induced alkaline secretion with

Address for correspondence: Prof Dr S J Konturek, Institute of Physiology, 31-5.31 Kraków, ul. Grzegorzecka 16. Poland.

Received for publication 20 October 1986. the maximal secretory capacity elicited by topical administration of prostaglandin (PG) $\mathrm{E}_{2}$ analogue; and (3) to evaluate the role of vagal cholinergic component in the mechanism of alkaline secretion in healthy subjects and duodenal ulcer patients.

\section{Methods}

SUBJECTS

Studies were carried out on 17 young healthy subjects and 16 duodenal ulcer patients (mean age 24 years, range 19-24; mean weight $73 \mathrm{~kg}$, range $69-78 \mathrm{~kg}$ ). Ten of the subjects had a history of DU disease documented previously by duodenoscopy but were asymptomatic with inactive ulcer at the time of the study and six others had typical ulcer symptoms and an active DU. The study was approved by the Human Research Review Committee and informed consent was obtained from each subject.

Eleven normal subjects and 10 DU patients under- 
went a basal modified sham feeding (MSF)-PGE 2 study (series A). Six normal subjects underwent basal modified sham feeding examination alone or combined with atropine or pirenzepine (series B). In six DU patients with active DU disease (series C), the basal modified sham feeding studies were done before, and three to four months after, selective gastric vagotomy.

\section{SECRETORY PROCEDURE}

The experiments were carried out after an overnight fast. In the evening of the day before the examination and the morning, about two hours before the experiment, subjects ingested $900 \mathrm{mg}$ ranitidine (Glaxo, England) with water. In all tests during the examination, ranitidine was infused intravenously at a dose of $50 \mathrm{mg} / \mathrm{h}$ throughout the experiment. Such pretreatment resulted in a complete suppression of gastric acid secretion (luminal $\mathrm{pH} 7 \cdot 0$ or above) and prevented any conversion of $\mathrm{HCO}_{3}$ to $\mathrm{CO}_{2}$.

Double lumen gastroduendal Dreiling tube with endotracheal cuff was inserted and positioned under fluoroscopic control with the cuff inflated just distally to the pylorus to prevent any escape of gastric perfusate into the duodenum or any reflux of the duodenal content into the stomach as described before. ${ }^{y}$ The tube with openings located in the distal portion of the stomach was used to continuously aspirate gastric content. An additional polyethylene catheter attached to the tube with openings in the proximal part of the stomach was used to perfuse the stomach with saline adjusted to $\mathrm{pH} 6.0$ and containing phenol red as a non-absorbable marker (40 $\mu \mathrm{g} / \mathrm{ml})$. The rate of gastric perfusion was $600 \mathrm{ml} / \mathrm{h}$. The perfusion-aspiration procedure was carried out throughout the examination. The volume of gastric perfusate was measured and the bicarbonate content was determined by back titration of the gastric perfusate to original $\mathrm{pH}(6 \cdot 0)$ as described previously. ${ }^{11}$ The samples of the perfusates were saved for phenol red determination (by spectrophotometry at $520 \mathrm{~nm}$ after being alkalinised to $\mathrm{pH} 11.5$ ) and for $\mathrm{PGE}_{2}$ radioimmunoassay as described before."

In some studies the motor activity of the stomach was monitored by means of perfused manometric catheter attached to the Dreiling tube with wide side openings located in the gastric antrum. Measurements were carried out using technique described before $^{12}$ during alkaline secretion and after modified sham feeding with subsequent administration of $16,16 \mathrm{DMPGE}_{2}$.

\section{EXPERIMENTAL DESIGN}

Several series of secretory tests were carried out. In the basal-MSF-PGE 2 experiments (series A), 60-120 min of basal collection and motility recordings were carried out in all subjects of this group followed by 15 minutes of the modified sham feeding during which the subjects were given roast beef and French fries as described..$^{13}$ Gastric perfusion-aspiration procedure was continued for 90 minutes after modified sham feeding. Finally, 16,16-dimethyl $\mathrm{PGE}_{2}\left(\mathrm{PGE}_{2}\right)$ was introduced into the stomach in a dose of $5 \mu \mathrm{g} / \mathrm{kg}$ dissolved in $20 \mathrm{ml}$ saline $(\mathrm{pH} 6.0)$ and kept there for 15 minute period. In the preliminary study in ranitidine treated subjects, this dose of $\mathrm{PGE}_{2}$ caused a maximal stimulation of alkaline secretion. After the application of $\mathrm{PGE}_{2}$, the residual gastric content was removed and the perfusion-aspiration procedure was restarted for the final 60 minute period. In separate tests on five healthy subjects basal $\mathrm{HCO}_{3}$ secretion was examined for a 60 minute period and then gastrin heptadecapeptide (gift of Professor E Wunsch, Max Planck Institute, Munich, Germany) or human PP (gift of Dr R E Chance, Elli Lilly Co, Indianapolis, IN) was infused intravenously in two doses each for one hour.

In tests with anticholinergics (series B), basalmodified sham feeding- $\mathrm{PGE}_{2}$ examination alone was first carried out and then, in another test day, basal alkaline secretion was measured. Atropine or pirenzepine was injected intravenously in bolus doses $(5-20 \mu \mathrm{g} / \mathrm{kg})$ doubled every 30 minute period. Finally, modified sham feeding followed by $\mathrm{PGE}_{2}$ administration was carried out and the gastric perfusion-aspiration procedure was continued for next 120 minutes.

In six DU patients with active ulcer who were submitted to gastric vagotomy (series $\mathrm{C}$ ), the basalmodified sham feeding- $\mathrm{PGE}_{2}$ examination was performed before and three to four months after the operation. In all these patients, insulin test was also carried out to determine the completeness of vagotomy as judged by 'positive' or 'negative' multiple criteria. ${ }^{1+}$

In some subjects tested in series $\mathrm{A}$, basal acid secretion and maximal, pentagastrin $(2 \mu \mathrm{g} / \mathrm{kg} / \mathrm{h})$ stimulated acid outputs were also determined.

\section{ASSAYS}

Venous blood samples were drawn before, during and after modified sham feeding tests and as well as in tests with infusion of exogenous gastrin or polypeptide in series A subjects for gastrin and polypeptide determinations by specific radioimmunoassay as described before..$^{13}$ All determinations were performed in duplicate. The radioimmunoassay system was sufficiently sensitive to detect $2.5 \mathrm{pg} / \mathrm{ml}$ plasma gastrin and $5 \mathrm{pg} / \mathrm{ml}$ plasma PP.

Results are expressed as means +SEM. Student's $t$ test was used to determine statistical significance. Differences with $p<0.05$ were considered significant. 


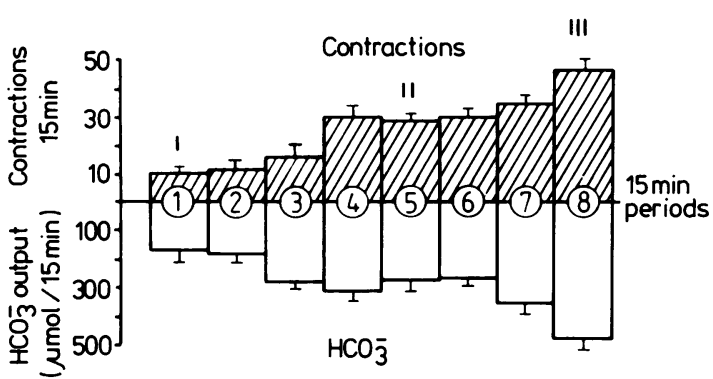

Fig. 1 Mean + SEM of gastric contractions and $\mathrm{HCO}_{3}$ outputs during one MMC cycle in 17 healthy subjects.

\section{Results}

The mean+SEM of basal $\mathrm{HCO}_{3}$ secretion in 17 healthy subjects was $1120 \pm 124 \mu \mathrm{mol} / \mathrm{h}$ and in $10 \mathrm{DU}$ patients (series A) was $880 \pm 72 \mu \mathrm{mol} / \mathrm{h}$. The difference in basal alkaline secretion between normal and DU patients was not statistically significant. The values of $\mathrm{HCO}_{3}$ outputs in the individual subjects changed in phase with gastric motor activity. The $\mathrm{HCO}_{3}$ secretion fell the lowest values during phase I, then showed a small but insignificant rise during phase II to reach significant (over phase I value) peak at phase III ('activity front') when the rate of gastric contractions reached the peak (about $3 / \mathrm{min}$ ). The mean interval between two consecutive gastric activity fronts averaged $94 \pm 6$ minutes in healthy subjects and it was similar to that in DU patients $(88 \pm 10 \mathrm{~min})$. The mean values of gastric contractions and gastric alkaline secretion in all healthy subjects tested during one MMC cycle are shown on Figure 1.

No significant correlation was found between basal

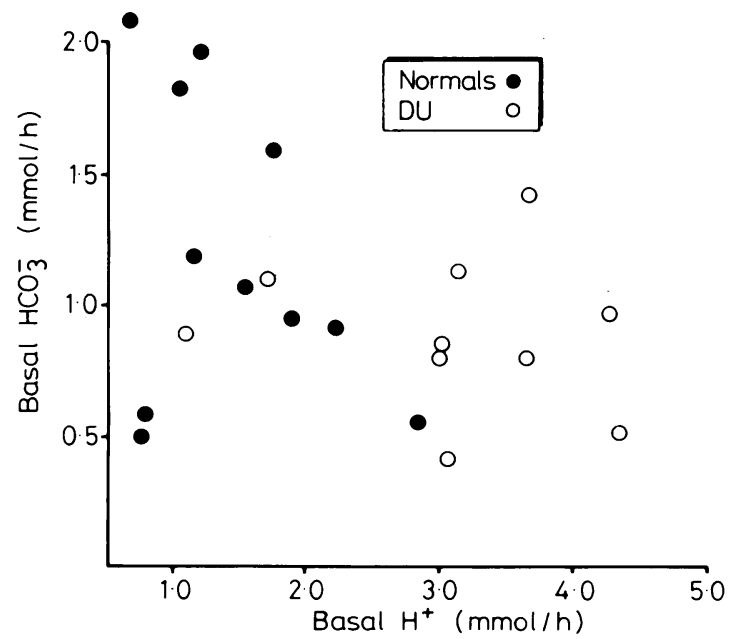

Fig. 2 Relationship between basal gastric $\mathrm{HCO}_{3}$ and basal $\mathrm{H}+$ outputs in 11 healthy subjects and $10 \mathrm{DU}$ patients.

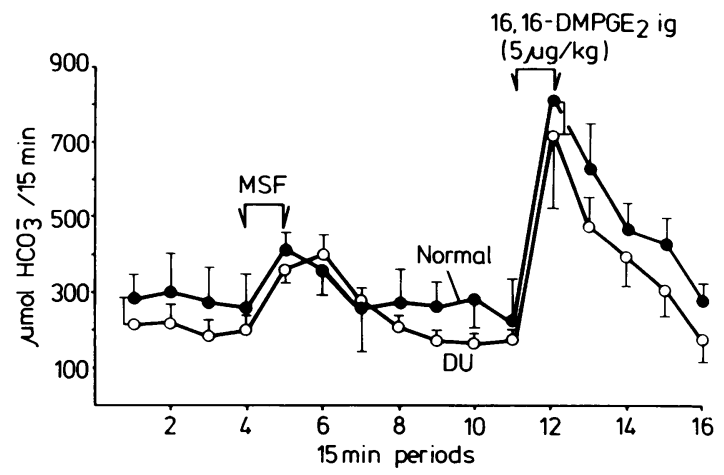

Fig. 3 Effects of modified sham feeding and intragastric administration of $\mathrm{PGE}_{2}$ analogue on gastric $\mathrm{HCO}_{3}$ outputs in 11 healthy subjects and 10 DU patients.

$\mathrm{HCO}_{3}$ and basal $\mathrm{H}+$ outputs (Fig. 2). Similarly no correlation was found between maximally stimulated $\mathrm{HCO}_{3}$ outputs (induced by $\mathrm{PGE}_{2}$ ) and maximally stimulated $\mathrm{H}+$ outputs (induced by pentagastrin) in both normal subjects and DU patients and these results have been omitted for the sake of clarity.

Modified sham feeding caused almost immediate increase in gastric $\mathrm{HCO}_{3}$ secretion reaching peak during or immediately after the modified sham feeding period. The increase in $\mathrm{HCO}_{3}$ output above basal level was significant and reached in healthy subjects and DU patients about $28 \%$ and $36 \%$ of the maximal alkaline response to exogenous $\mathrm{PGE}_{2}(5 \mu \mathrm{g} / \mathrm{kg})$ in these subjects (Fig. 3). In the preliminary study on five healthy subjects this dose of $\mathrm{PGE}_{2}$ analogue produced the highest increase in $\mathrm{HCO}_{3}$ secretion amounting to about $1070 \pm 210 \mu \mathrm{mol} / 30 \mathrm{~min}$. Lower doses of $\mathrm{PGE}_{2}$ such as $0 \cdot 6,1 \cdot 2$, and $2.5 \mu \mathrm{g} / \mathrm{kg}$ produced, respectively, $680 \pm 132,840 \pm 110$, and $1010 \pm 280 \mu \mathrm{mol} / 30 \mathrm{~min}$ in these subjects. The increase in $\mathrm{HCO}_{3}$ secretion in response to modified sham feeding was accompanied by a significant

Table 1 Mean ( $\pm S E M)$ plasma concentrations of gastrin and $P P$ and gastric luminal contents of $P G E_{2}$ during basal alkaline secretion and 15 min after the start of the modified sham feeding in healthy subjects and DU patients

\begin{tabular}{llll}
\hline & $\begin{array}{l}\text { Plasma } \\
\text { gastrin }(p M)\end{array}$ & $\begin{array}{l}\text { Plasma } \\
P P(p M)\end{array}$ & $\begin{array}{l}\text { Luminal release } \\
P G E_{2}(n g / 15 \mathrm{~min})\end{array}$ \\
\hline $\begin{array}{l}\text { Normal subjects } \\
\text { Basal }\end{array}$ & $32 \cdot 2 \pm 5 \cdot 1$ & $28 \cdot 6 \pm 3 \cdot 7$ & $37 \cdot 9 \pm 4 \cdot 8$ \\
$\begin{array}{l}\text { MSF } \\
\text { Duodenal ulcer }\end{array}$ & $39 \cdot 5 \pm 6 \cdot 4$ & $47 \cdot 6 \pm 6 \cdot 6^{*}$ & $53 \cdot 6 \pm 8 \cdot 2^{*}$ \\
$\quad \begin{array}{l}\text { Basal } \\
\text { MSF }\end{array}$ & $29 \cdot 4 \pm 4 \cdot 4$ & $32 \cdot 2 \pm 4 \cdot 5$ & $41 \cdot 3 \pm 5 \cdot 7$ \\
\hline
\end{tabular}

*Significant $(p<0 \cdot(05)$ increase above basal level. 
Table 2 Mean ( $\pm S E M)$ gastric alkaline secretion and plasma gastrin and polypeptide concentrations in five healthy subjects under basal conditions and during intravenous infusion of gastrin (20 and $200 \mathrm{pmol} / \mathrm{kg} / \mathrm{h})$ of polypeptide $(25$ and $250 \mathrm{pmol} / \mathrm{kg} / \mathrm{h}$ )

\begin{tabular}{|c|c|c|c|c|}
\hline & & $\begin{array}{l}\text { Gastric } \\
\mathrm{HCO}_{3} \\
(\mu \mathrm{mol} / \mathrm{h})\end{array}$ & $\begin{array}{l}\text { Plasma } \\
\text { gastrin } \\
(p M)\end{array}$ & $\begin{array}{l}\text { Plasma } \\
P P \\
(p M)\end{array}$ \\
\hline \multicolumn{2}{|l|}{ Basal } & $1080 \pm 144$ & $29 \pm 3$ & $22 \pm 4$ \\
\hline \multicolumn{2}{|c|}{ Gastrin $20 \mathrm{pmol} / \mathrm{kg} / \mathrm{h}$} & $860 \pm 106$ & $42 \pm 6$ & $26 \pm 3$ \\
\hline 200 & , & $948 \pm 128$ & $322 \pm 28^{*}$ & $33 \pm 4$ \\
\hline \multirow[t]{2}{*}{ PP } & , & $1150 \pm 184$ & $26 \pm 5$ & $43 \pm 6^{*}$ \\
\hline & " & $1260 \pm 210$ & $22 \pm 4$ & $326 \pm 42$ \\
\hline
\end{tabular}

*Significant $(\mathrm{p}<0 \cdot 05)$ increase above the basal level.

increase in luminal release of $\mathrm{PGE}_{2}$ and plasma PP but not gastrin level (Table 1).

In tests with infusion of exogenous gastrin or human PP, plasma hormone concentration was in the range or several times higher than those recorded after modified sham feeding. No significant changes in gastric $\mathrm{HCO}_{3}$ outputs were recorded after the administration of exogenous gastrin or PP (Table 2).

Atropine injected intravenously in subjects of $B$ series reduced dose dependently basal alkaline secretion and completely abolished the alkaline response to modified sham feeding (Figs 4 and 5). In contrast, pirenzepine injected in the same dose range did not significantly affect basal alkaline secretion and failed to alter the increment in alkaline secretion induced by modified sham feeding in these subjects. Neither atropine nor pirenzepine significantly affected the increment in alkaline secretion induced by intragastric administration of $\mathrm{PGE}_{2}$ analogue and these results are omitted for the sake of clarity.

In patients with active DU, basal and modified

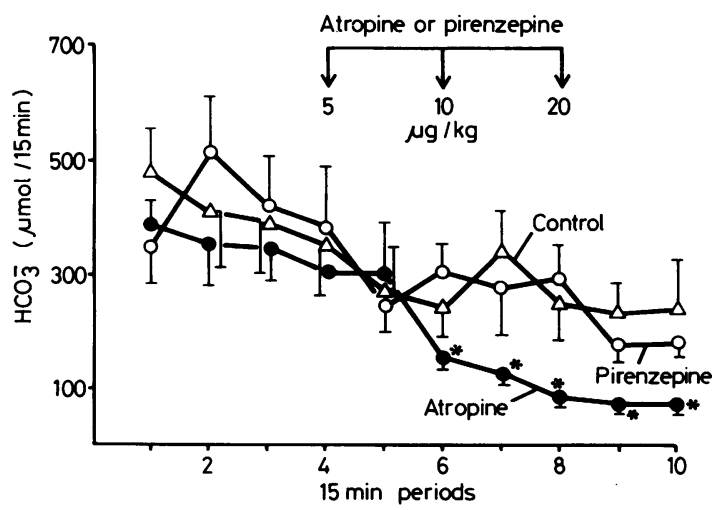

Fig. 4 Effects of graded doses of atropine and pirenzepine on basal gastric $\mathrm{HCO}_{3}$ secretion in healthy subjects. Mean + SEM of six tests on 6 healthy subjects.

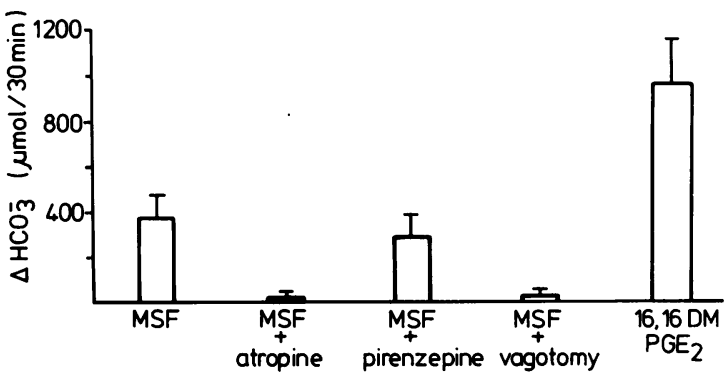

Fig. 5 The mean (+SEM) increments (over basal) in $\mathrm{HCO}_{3}$ outputs in response modified sham feeding, to modified sham feeding + atropine or pirenzepine, to modified sham feeding performed after selective gastric vagotomy to intragastric administration of 16,16dimethyl $P G E_{2}$ in 11 healthy subjects and $10 \mathrm{DU}$ patients.

sham feeding-induced alkaline secretion was similar to that recorded in other patients with inactive peptic ulcer (series C). After vagotomy, basal alkaline secretion was unchanged but modified sham feeding failed to increase this secretion (Fig. 5). Intragastric administration of $\mathrm{PGE}_{2}$ analog resulted in similar increase in gastric alkaline secretion as before the vagotomy and these results are not included. In all these subjects, vagotomy was complete as judged by insulin tests performed about 10 days before the examination.

\section{Discussion}

This study shows that in man, basal gastric alkaline secretion fluctuates in phase with gastric motor activity reaching peaks at the phase III of MMC and markedly increases after vagal stimulation to reach about $30 \%$ of the maximal alkaline response to exogenous $\mathrm{PGE}_{2}$.

In the present study we used a validated technique for measuring alkaline secretion by simple back titration of gastric perfusate to the original $\mathrm{pH} 6 \cdot 0.1$ Complete blockade of gastric acid secretion by large dose of ranitidine to maintain luminal neutrality and the occlusion of the duodenal bulb with inflated culf to prevent any reflux of the duodenal content to the stomach created favourable intragastric conditions for the complete recovery and reliable determination of $\mathrm{HCO}_{3}$ output without any conversion of $\mathrm{HCO}_{3}$ to $\mathrm{CO}_{2}$. Our basal $\mathrm{HCO}_{3}^{-}$output was about twice as large as that calculated in another study from the intragastric $\mathrm{pH}$ and $\mathrm{pCO}_{2}$ using the HendersonHasselbach equation. The latter technique assumes that $\mathrm{CO}_{2}$ in the gastric lumen originates from the neutralisation of secreted $\mathrm{HCO}_{3}^{-}$by $\mathrm{H}+$. A diffusion or the escape of $\mathrm{CO}_{2}$ from the gastric lumen, particularly when gastric neutrality was not main- 
tained, could be a possible source of an error and could underestimate the rate of alkaline secretion. ${ }^{\circ}$ In contrast, basal alkaline secretion estimated from the two component model of gastric secretion was reported to be two to three times higher than that found in the present study. These higher values of alkaline secretion originate from two assumptions of this model; (1) that the $\mathrm{HCl}$ concentration in the primary parietal secretion in man is $160 \mathrm{mmol}$, the value much higher than estimated by others, ${ }^{15}$ and (2) that the relation between the osmolarity of the plasma and the osmolarity of the parietal and nonparietal secretion are constant. Both these assumptions may be incorrect and thus resulting in overestimation of gastric alkaline secretion in man. ${ }^{8}$

This study shows that basal or maximal alkaline secretion (induced by $\mathrm{PGE}_{2}$ analogue) is not correlated with the respective basal or maximal (induced by pentagastrin) acid secretion. We confirmed previous reports that gastric alkaline secretion in normal subjects does not differ significantly from that in DU patients $^{16}$ and no correlation was found between basal or maximal $\mathrm{H}+$ and $\mathrm{HCO}_{3}^{-}$outputs in normal subjects or DU patients. These disagree with recent suggestions of the deficiency of $\mathrm{HCO}_{3}^{-}$output in DU patients $^{17}$ as well as with the postulate of excessive alkaline secretion in DU disease presumably caused by a higher rate of non-parietal secretion. ${ }^{16}$ The reason for these discrepancies is not known but it could be because of the calculation of $\mathrm{HCO}_{3}$ outputs based on two component model of gastric secretion which might overestimate the actual rate of gastric alkaline secretion. ${ }^{16}$

According to our results, the rate of alkaline secretion is not constant but shows cyclic fluctuations reaching peaks at phase III of the gastric MMC. Such periodic fluctuations of gastric acid or pancreatic enzyme secretion were reported previously in man but this study described for the first time that gastric alkaline secretion is also in close relation to gastric motility. The mechanism of the secretory and motor periodicity of the digestive functions remains unclear but both neural and endocrine factors have been implicated.."

There is little doubt that vagal cholinergic component contributes to the gastric alkaline secretion. Our finding that atropine reduces dose dependently basal alkaline secretion without affecting the secretory stimulation by exogenous $\mathrm{PGE}_{2}$ suggests that basal cholinergic drive has a substantial influence on alkaline secretion. This drive is probably of local intramural origin because it remained unchanged after complete vagotomy. On the other hand, vagal nerves appear to have a potent stimulatory influence on alkaline secretion as shown by a marked rise in this secretion after physiological vagal excitation such as sham feeding ${ }^{7 \times}$ and almost complete removal of this excitation by vagotomy. The mechanism of the modified sham feeding-induced $\mathrm{HCO}_{3}^{-}$secretion is unknown. As modified sham feeding increased the release of plasma gastrin and $\mathrm{PP}$, which are under vagal-cholinergic control and which were shown to stimulate $\mathrm{HCO}_{3}$ in dogs, ${ }^{19}$ we carried out separate tests to determine whether these gut hormones could contribute to the vagally stimulated $\mathrm{HCO}_{3}^{-}$secretion. Unlike in dogs, ${ }^{19}$ neither gastrin nor polypeptide affected gastric $\mathrm{HCO}_{3}^{-}$secretion indicating that the vagally induced $\mathrm{HCO}_{3}^{-}$in man does not depend upon the action of those hormones. The vagal-cholinergic stimulation of gastric alkaline secretion was accompanied by a significant increase in luminal release of $\mathrm{PGE}_{2}$ but it appears to be independent from that induced by $\mathrm{PGE}_{2}$ as neither atropine nor vagotomy affected the secretory stimulation by $\mathrm{PGE}_{2}$. It is of interest, that vagally stimulated gastric alkaline secretion, as well as vagally induced acid secretion did not reach the maximal secretory capacity elicited by $\mathrm{PGE}_{2}$ and pentagastrin, respectively. This could be explained that modified sham feeding is only a submaximal stimulus for gastric acid-alkaline secretion or that both stimulatory and inhibitory mechanisms are activated simultaneously by vagal activation.?

It is of interest that vagal-cholinergic component of gastric alkaline secretion is not blocked by pirenzepine, a highly specific antimuscarinic agent acting via $M$ muscarinic receptors. ${ }^{2021}$ Our finding that pirenzepine does not interfere with basal or vagally stimulated alkaline secretion may explain the well characterised gastroprotective ${ }^{21}$ and antiulcer activity $^{2122}$ of this drug. Benzilonium bromide another anticholinergic, was reported to abolish modified sham feeding induced alkaline secretion as did atropine, but failed to affect basal alkaline secretion. ${ }^{7}$ This suggests that various anticholinergics act on alkaline secretion via different mechanisms and various subtypes of muscarinic receptors.

\section{References}

1 Flemstrom G, Garner A, Gastroduodenal HCO3 transport: characteristics and proposed role in acidity regulation and mucosal protection. Am J Physiol 1982; 242: G183-93.

2 Flemstrom G, Turnberg LA. Gastroduodenal defence mechanisms. Clin Gastroenterol 1984; 13: 327-54.

3 Feldman M, Barnett CC. Gastric bicarbonate secretion in humans. J Clin Invest 1983; 72: 295-303.

4 Thor P, Konturek JW, Konturek SJ. Cyclic changes in duodenal myoelectric activity and duodenal alkaline secretion in fasted dogs. Role of vagus and prostaglandins. Gastroenterology 1966; 90: 1667. 
5 Konturek SJ, Bilski J, Tasler J. Cephalic phase of gastric and duodenal alkaline secretion in conscious dogs. Gastroenterology 1986; 90: 1499.

6 Feldman M. Gastric $\mathrm{H}+$ and $\mathrm{HCO} 3$ secretion in response to sham-feeding in humans. Am J Physiol 1985; 248: G188-91.

7 Forsell H, Stenquist B, Olbe L. Vagal stimulation of human gastric bicarbonate secretion. Gastroenterology 1985; 89: 581-6.

8 Flemstrom G. Measurement of gastric bicarbonate secretion. Gastroenterology 1985; 88: 2000-1.

9 Konturek SJ, Biernat J, Kwiecien N, Oleksy J. Effect of glucagon on meal-induced gastric secretion in man. Gastroenterology 1975; 68: 448-54.

10 Konturek SJ, Tasler J, Bilski J, Kania J. Prostaglandins and alkaline secretion from oxyntic, antral and duodenal mucosa. Am J Physiol 1983; 245: G539-46.

11 Konturek SJ, Bilski J, Tasler J. Gastroduodenal alkaline response to acid and taurocholate in conscious dogs. $\mathrm{Am}$ J Physiol 1984; 247: G149-54.

12 Vantrappen G, Janssens J, Hellemans J, Ghoos Y. The interdigestive motor complex of normal subjects and patients with bacterial overgrowth of the small intestine. J Clin Invest 1977; 59: 1158-66.

13 Konturek SJ, Kwiecien N, Obtulowicz W, et al. Cephalic phase of gastric secretion in healthy subjects and duodenal ulcer patients. Role of vagal innervation. Gut 1987; 20: 875-81.

14 Gillespie G, Elder JB, Smith IS, et al. Analysis of basal acid secretion and its relation to the insulin response in normal and duodenal subjects. Gastroenterology 1972; 62: 903-11.

15 Makhlouf GM. Electrolyte composition of gastric secretion. In: Johnson LR, ed. Physiology of the gastrointestinal tract. New York: Raven Press, 1981: 551-66.

16 Feldman M, Barnett CC. Gastric bicarbonate secretion in patients with duodenal ulcer. Gastroenterology 1985; 88: $1205-8$.

17 Isenberg JI, Selling JA, Hogan DL, Thomas F, Koss MA. Duodenal ulcer patients have impaired proximal duodenal mucosal bicarbonate secretion. Gastroenterology 1986; 90: 1472.

18 Vantrappen G, Peeters TL, Janssens J. The secretory component of the interdigestive migrating motor complex in man. Scand J Gastroenterol 1979; 14: 663-8.

19 Konturek SJ, Bilski J, Tasler J, Laskiewicz J. Gut hormones in stimulation of gastroduodenal alkaline secretion in conscious dogs. Am J Physiol 1985; 248: G687-91.

20 Walan A. Antacids and anticholinergics in the treatment of duodenal ulcer. Clin Gastroenterol 1984; 13: 473-99.

21 Jaup B. The mode of action of pirenzepine in man with special reference to its anticholinergic muscarinic properties. Scand J Gastroenterol 1981; 68: suppl. 1-26.

22 Konturek SJ, Brzozowski T, Radecki T, Piastucki I. Gastric cytoprotection by pirenzepine: Role of endogenous prostaglandins. Scand J Gastroenterol 1982; 17: suppl. 72: 251-4. 